\title{
Chemical and Electrochemical Investigations of Spider Wisp / Cat's Whiskers (Cloeme Gynandra) as Corrosion Inhibitor for Mild Steel in Hydrochloric Acid Medium
}

\author{
Alfred Ikpi Onen*1, Dzaradiya Umar Yakubu \\ ${ }^{1}$ Department of Chemical Sciences, Federal University, Wukari, Taraba State, Nigeria. \\ ${ }^{2}$ Department of Chemical Science and Technology, Federal Polytechnic, Mubi, Adamawa State. \\ Nigeria
}

\begin{abstract}
The inhibitive effect of Spider Wisp / Cat's Whiskers (Cloeme gynandra) on the corrosion of mild steel in $0.1 \mathrm{M} \mathrm{HCl}$ has been investigated by means of gravimetric analysis and Electrochemical (polarization) studies at 308,318 and 328K. A marked decrease of the corrosion rate (CR) was observed with increasing extracts concentration. An effective inhibition with $94.14 \%$ - 92.68\% efficiency $\left(I_{E} \%\right)$ was reached at $100 \mathrm{mg}$ inhibitor concentration as the temperature increased from $308-328 \mathrm{~K}$. The effect of temperature showed a decreasing $I_{E} \%$ with increasing temperature. The average value of activation energy, Ea is $27.40 \mathrm{kJmol}^{-1}$ which is lower than $40.00 \mathrm{kJmol}^{-1}$ implying that the inhibitor is physically adsorbed on the mild steel surface. The value of heat of adsorption, Qads, having average of $-13.95 \mathrm{kJmol}^{-1}$, is an indication that inhibition efficiency and adsorption decrease with increase in temperature. Results clearly revealed that Spider Wisp / Cat's Whiskers inhibition activity proceeds via a physisorption. The adsorption of Spider Wisp / Cat's Whiskers onto the mild steel surface followed a Langmuir isotherm. Corrosion current $\left(I_{\text {corr }}\right)$ density decreases in the presence of plant extract and the inhibition rate increases with increasing extract concentration which provides evidence for the inhibitive effect of the plants extract in $\mathrm{HCl}$ medium. The presence of Alkaloid, Flavonoid and Tannin is also an evidence of the inhibition potency of the extract. FT-IR results indicate that Spider Wisp / Cat's Whiskers (Cleome gynandra) contain heteroatom such as $\mathrm{O}, \mathrm{N}$, and multiple bonds in the molecule through which they adsorption takes place on the metal surface. Adsorption depends mainly on certain physicochemical properties of the inhibitor group, such as functional groups.
\end{abstract}

Keywords: Spider Wisp / Cat's Whiskers, inhibition, polarization, physisorption, FT-IR

\section{INTRODUCTION}

Protection against corrosion, the electrochemical destruction of metallic structures occurring through gradual anodic dissolution, represents a vital concern for many industries. This phenomena is typically favored on less noble metals (mainly iron, aluminum, copper, zinc, magnesium and their alloys) when exposed to corrosive environment such as acids. Hydrochloric acid is widely used in removing scale and salts from steel surfaces, cleaning tanks and pipelines and steel alloys (Ahmad et al., 2010).

The most effective and efficient organic inhibitors are compounds that have multiple bonds. The biological toxicity of these products, especially organic phosphates, has been documented specifically about their environmental harmful characteristics. From the standpoint of safety, the development of non-toxic and effective inhibitors is considered more important and desirable nowadays, which are also called eco-friendly or green corrosion inhibitors (Manimegalai et al., 2000).

These toxic effects have led to the use of natural products as anticorrosion agents which are ecofriendly and harmless. In recent years, many alternative eco-friendly corrosion inhibitors have been studied and developed. They range from rare earth elements to organic compounds (Manimegalai et al., 2000).

Over the years, corrosion is receiving more and more attention because it causes damage to materials in a direct or indirect way. Scientists have been trying to understand and control corrosion for as long as they have used iron or steel. Thus, how to set a practical and general kinetic model to study the corrosion inhibition of organic compounds for metals corrosion in acidic media is becoming more and 
more urgent (Guannanet al., 2002). A large number of nations spend about $6 \%$ of their total gross domestic product in addressing corrosion-related issues, this is not economical. Consequently, there is a need to investigate and produce cost-effective and non-toxic methods for reducing, preventing, and treating corrosion. The chemical process industry is one of the largest and most economically important groups of industries that are committed to this effort (Guannanet al., 2002).

Spider Wisp / Cat's Whiskers (Cloeme gynandra) plant serves as inhibitor for microorganisms and has rich sources of ingredients which have high inhibition potency. However, the leaf extract has not been used on corrosion inhibition of mild steel in hydrochloric acid solution. To explore this possibility, an attempt has been made to evaluate the inhibition efficiency of the extract in $0.1 \mathrm{M} \mathrm{HCl}$ solution using weight loss and potentio dynamic polarization techniques. This study is also aimed at characterizing the functional groups in CGleaves extract using FT-IR and to determine the temperature dependence on corrosion rates.

\section{MATERIALS AND MethodS}

\subsection{Sampling and Sample Preparation}

Mild steel (MS) sheets of purity $98 \%$ was obtained from Mubi North metropolis of Adamawa State in Nigeria. Each sheet of thickness $0.1 \mathrm{cmwas}$ mechanically press-cut into coupons of dimensions $2 \times 5$ $\mathrm{cm}$. The coupons was descaled using wire brush and degreased in absolute ethanol, dried in propanone, weighed and store in moisture-free desiccator prior to use. Solvents used for the extraction of plant was methanol of analytical grade as adopted by Aydogdu and Aydinol, (2006); Onen et al.,(2013).

Leaves of Cleome gynandra were collected from a nearby bush in Mubi North, Adamawa State, Nigeria. The leaves were air dried and pulverized, stored in air tight container for the analysis as adopted by Aydogdu and Aydinol, 2006;Onen et al., 2013.

\subsection{Gravimetric Measurements}

The procedure reported earlier by Onen et al., (2013) collaborated by Oguzieet al., (2014) was adopted for the gravimetric measurements.

The corrosion rate, $\mathrm{CR}=\frac{\Delta m}{A T}$

Where $\Delta m=$ change in the weight loss of MS(g)

A is the area of MScoupons $\left(\mathrm{cm}^{2}\right)$

$\mathrm{T}$ is the time of exposure (hours)

The percentage inhibition efficiency, $\left(\% \mathrm{I}_{\mathrm{E}}\right)$ was calculated using the expression

$\% \mathrm{IE}=\frac{\Delta m o-\Delta m i}{\Delta m o} \times 100$

$\Delta m o$ Change in weight loss of mild steel without inhibitor $(\mathrm{g})$

$\Delta m i \quad$ Change in weight loss of mild steel with inhibitor $(\mathrm{g})$

Surface coverage, $\theta=\frac{m o-m i}{m o}$

\subsection{Electrochemical Measurements}

Electrochemical experiment was carried out using a conventional electrolyte cell with three-electrode arrangement: saturated potassium chloride reference electrode $(\mathrm{Ag} / \mathrm{AgCl}$ Sat, $3 \mathrm{M} \mathrm{KCl})$, platinum wire as counter electrode, and the MS bar as the working electrode (WE). Prior to each experiment, the specimen were polished with a series of emery papers of different grit sizes, polished with $\mathrm{Al}_{2} \mathrm{O}_{3}(0.5 \mathrm{~mm}$ particle size), washed several times with bi-distilled water then with propanone and dried in a stream of air. The electrode potential was allowed to stabilize 30 minutes before starting the measurements. The aggressive environment used was $0.1 \mathrm{M} \mathrm{HCl}$ solution with different concentrations of the extracts. All experiments were conducted at $308 \mathrm{~K}$. The exposed electrode area to the corrosive solution was $9.00 \mathrm{~cm}^{2}$ (Hammoutiet al., 2013). 
Potentio dynamic polarization curves were obtained by changing the electrode potential automatically from (-6000 to $-400 \mathrm{mV}$ ) at open circuit potential. Measurement was performed with Autolab Instrument, model 302 using a computer interface fitted with Nova version 1.9 software (Hammoutiet al., 2013).

\subsection{Fourier Transform Infrared}

The procedure used for Fourier Transform Infrared (FT-IR) spectroscopy is as reported by Griffths and De-Hasseth, 2007using FT-IRPerkin Elmer Model. Analysis of the position, shape and intensity of the peaks in this spectrum revealed the details about the molecular structure of the sample(Griffths, and De-Hasseth, 2007).

\section{RESUlTS AND DisCUSSION}

\subsection{Effects of Temperature on Weight Loss Measurement}

The percentage inhibition efficiencies, corrosion rate and surface coverage for the different concentration of $\mathrm{HCl}$ and inhibitor is given in Table 1. The corrosion behaviour of MS in hydrochloric acid of different concentrations is given in Fig. 1. It is observed that increase in corrodent, $\mathrm{HCl}$ concentrations increase the mean weight loss of the MS. It is equally observed that as the temperature is increased, mean weight loss also increases.

Table1. Parameters for Mild steel corrosion in 0.1MHCl with inhibitor Spider Wisp / Cat's Whiskers at 308, 318 , and $328 \mathrm{~K}$

\begin{tabular}{|c|c|c|c|c|c|c|c|}
\hline $\begin{array}{l}\text { Inhibitor } \\
\text { concentration } \\
(\mathrm{mg} / \mathrm{L})\end{array}$ & 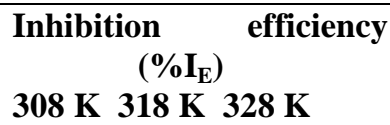 & $\begin{array}{r}\text { CoI } \\
\text { gcl } \\
308 \mathrm{~K}\end{array}$ & $\begin{array}{l}\text { osion } \\
-2 h^{-1}(x \\
318 K\end{array}$ & $\begin{array}{l}\text { ate } \\
\left.0^{-5}\right) \\
28 \mathrm{~K}\end{array}$ & $\begin{array}{l}\text { Surfa } \\
308 \mathrm{~K}\end{array}$ & $\begin{array}{c}\text { cove } \\
(\theta) \\
318\end{array}$ & $\begin{array}{l}\text { ge } \\
328 \mathrm{~K}\end{array}$ \\
\hline Blank & $\begin{array}{lll}- & - & - \\
\end{array}$ & 113.8 & 136.3 & 158.8 & - & - & - \\
\hline 20 & $91.5890 .21 \quad 89.76$ & 9.58 & 13.33 & 16.25 & 0.92 & 0.90 & 0.90 \\
\hline 40 & $\begin{array}{lll}92.67 & 91.44 & 90.81 \\
\end{array}$ & 8.33 & 11.67 & 14.58 & 0.93 & 0.91 & 0.91 \\
\hline 60 & $\begin{array}{lll}93.04 & 91.73 & 91.60\end{array}$ & 7.92 & 11.25 & 13.33 & 0.93 & 0.92 & 0.92 \\
\hline 80 & $\begin{array}{lll}93.77 & 92.66 & 92.13\end{array}$ & 7.08 & 10.00 & 12.50 & 0.94 & 0.93 & 0.92 \\
\hline 100 & $94.14 \quad 93.27 \quad 92.65$ & 6.67 & 9.17 & 11.67 & 0.94 & 0.93 & 0.93 \\
\hline
\end{tabular}

From Fig. 2, the mean weight loss of the MS is observed to decrease with increasing concentrations of the extract. Also mean weight loss decreases with increase in temperature, establishing that the additives are corrosion inhibitors for the MS in 0.1M hydrochloric acid medium. These observations are in agreement with those made by several researchers (Nooret al., (2016), Al Jahdaly and Awad (2016) and may be attributed to an increase in the rate of ionization and diffusion of the active ions and the fact that the higher the temperature, the faster the rate of corrosion reaction. The observed trend may also be due to the fact that rates of chemical reactions generally increase with acid concentration and also formation of film on the MS by the inhibitors, (as surface coverage). Surface coverage increases with increase in inhibitor concentration and decreases with increase in temperature, as shown in Table 1.

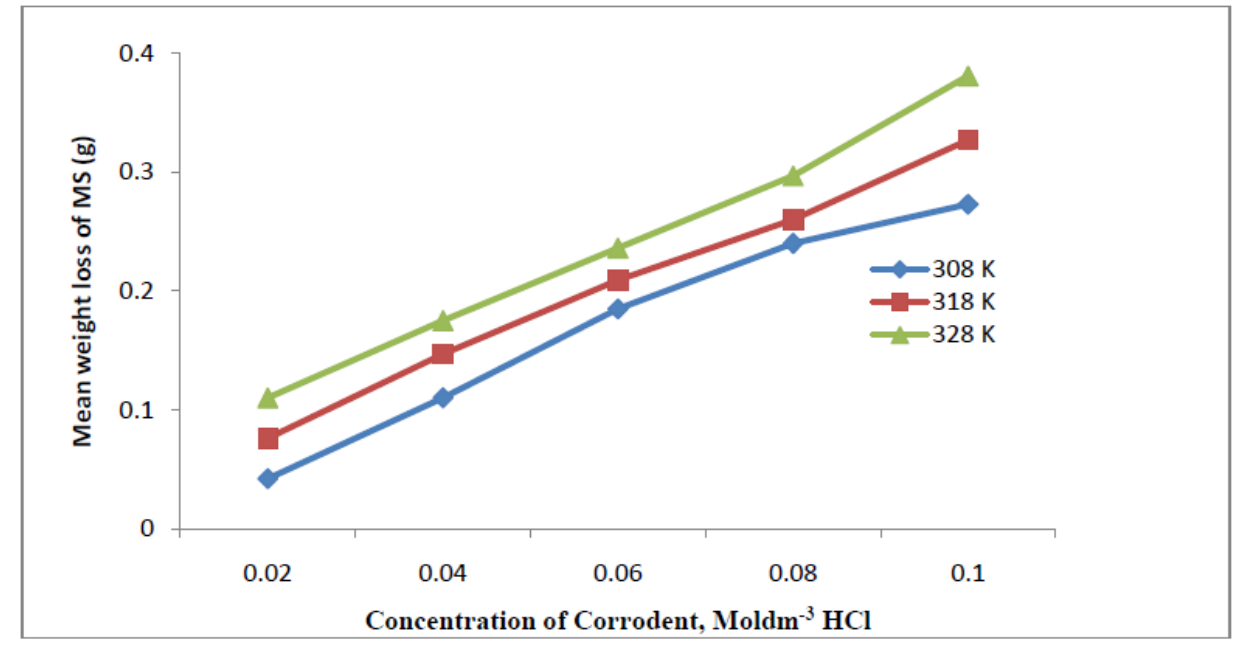

Fig1. Plot of Mean Weight loss of MS against various Concentrations of Corrodent, HCl at 308, 318 and $328 \mathrm{~K}$ 


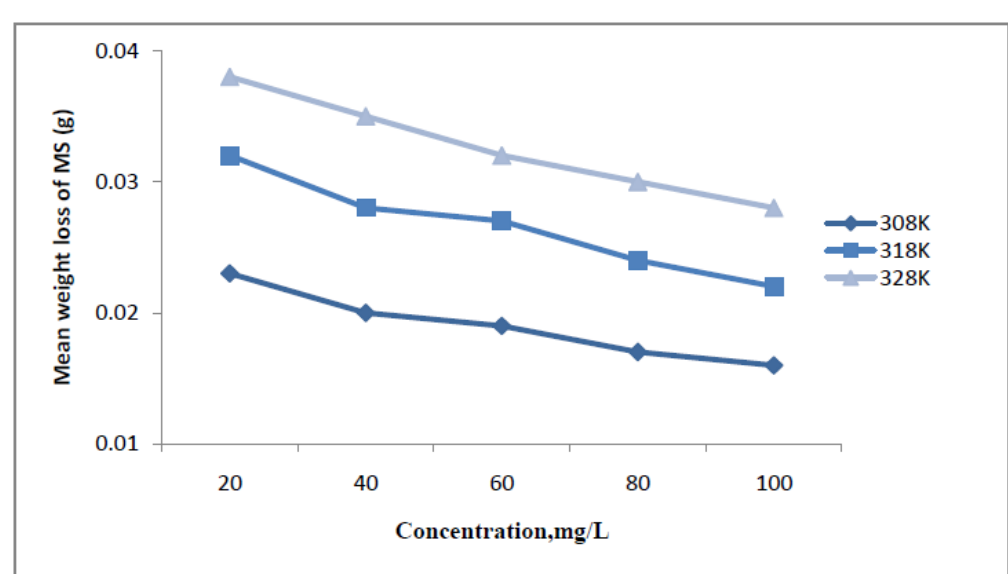

Fig2. Plot of Mean Weight loss of MS against various Concentrations of Inhibitor Spider Wisp / Cat's Whiskers at 308,318 and $328 \mathrm{~K}$

\subsection{Effect of Inhibitor Concentration on Percent Inhibition Efficiency}

Inhibition efficiency was determined using equation (2) and recorded in Table 1. Fig. 3 shows the plots of inhibition efficiency $\left(\% \mathrm{I}_{\mathrm{E}}\right)$ versus various concentrations of Spider Wisp / Cat's Whiskers respectively at 308,318 and $328 \mathrm{~K}$. It can be seen that inhibition efficiency $\left(\% \mathrm{I}_{\mathrm{E}}\right.$ ) increase with increasing concentration of the inhibitors but decrease with increasing temperature (308-328 K). This shows that the inhibitors function effectively at lower temperature. This trend of inhibition effectiveness is also confirmed from the polarization studies (Table 2). The decrease in inhibition efficiencies with increasing temperature shows that the time lag for the process of adsorptions of the inhibitor molecules on the MS surface becomes shorter. This observation is in agreement with report by Al-Senani (2016).

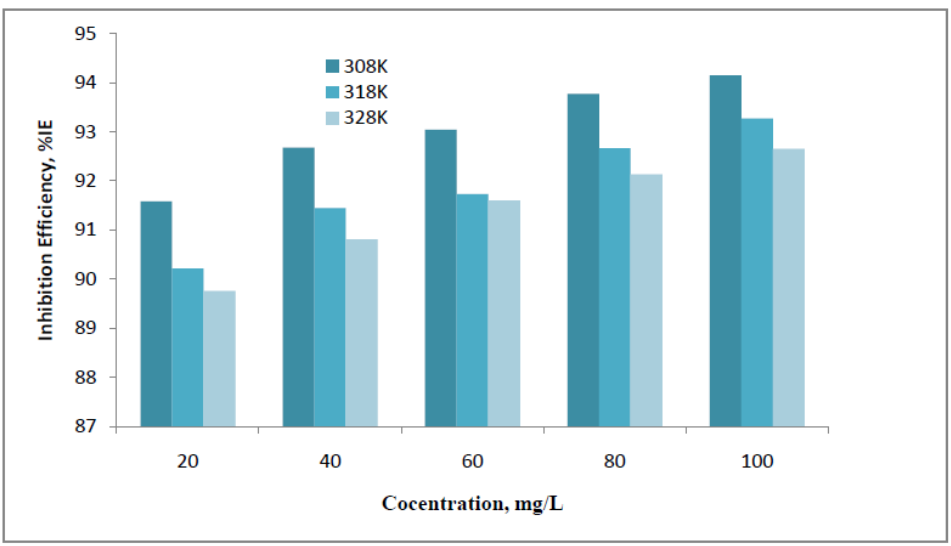

Fig3. Plot of Percentage Inhibition Efficiency $\left(\% I_{E}\right)$ of $M S$ against various Concentrations of Inhibitor Spider Wisp / Cat's Whiskers at 308, 318 and $328 \mathrm{~K}$

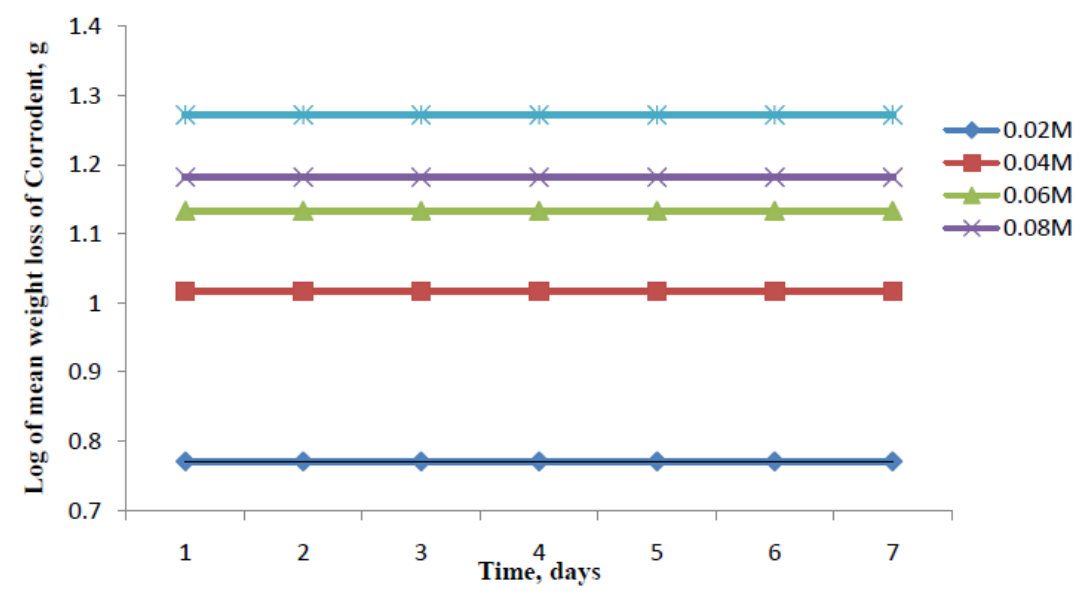

Fig4. Plot of Log of Mean Weight loss of MS against various Concentrations of the Corrodent for 7 days at 308 K 
Chemical and Electrochemical Investigations of Spider Wisp / Cat's Whiskers (Cloeme Gynandra) as Corrosion Inhibitor for Mild Steel in Hydrochloric Acid Medium

Table2. Thermodynamic Parameters for MS corrosion in $0.1 \mathrm{M} \mathrm{HCl}$ with inhibitors (Solanumscabrum and Cloeme gynandra) at 308, 318, and $328 \mathrm{~K}$

\begin{tabular}{|c|c|c|c|}
\hline $\begin{array}{l}\text { Inhibition } \\
\text { concentration }(\mathrm{mg} / \mathrm{L})\end{array}$ & $\begin{array}{l}\text { Mean weight loss } \\
308 \text { K } 318 \text { K } 328 \text { K }\end{array}$ & $\begin{array}{l}\text { Activationenergy, } \\
\text { Ea (kJ) 308-318 K }\end{array}$ & $\begin{array}{l}\text { Heat of adsorption } \\
\text { Qads }\left(\mathrm{kJmol}^{-1}\right) \text { 308-318 K }\end{array}$ \\
\hline Blank & $\begin{array}{lll}0.273 & 0.327 & 0.381\end{array}$ & 14.70 & \\
\hline 20 & $\begin{array}{lll}0.023 & 0.032 & 0.039\end{array}$ & 26.90 & -13.88 \\
\hline 40 & $\begin{array}{lll}0.020 & 0.028 & 0.035\end{array}$ & 27.46 & -14.63 \\
\hline 60 & $\begin{array}{llll}0.019 & 0.027 & 0.032 \\
\end{array}$ & 28.59 & -15.00 \\
\hline 80 & $\begin{array}{lll}0.017 & 0.024 & 0.030\end{array}$ & 28.12 & -15.00 \\
\hline 100 & $\begin{array}{lll}0.016 & 0.022 & 0.028 \\
\end{array}$ & 25.93 & -11.25 \\
\hline Average & & 27.40 & -13.95 \\
\hline
\end{tabular}

\subsection{Kinetic and Thermodynamic Analysis of the Results}

Plots of logarithm mean weight loss versus time (days) at $308 \mathrm{~K}$ in different concentrations of hydrochloric acid (without inhibitor) is shown in Fig. 4. Linear variations were observed from these plots which signify first order kinetics for the inhibition process.

The activation energies, Ea, recorded in Table 2 were determined using the equation;

$E a=2.303 R\left(\frac{T 1 T 2}{T 2-T 1}\right) \log \frac{\rho 2}{\rho 1}$

where $\rho_{1}$ and $\rho_{2}$ are corrosion rates at $308 \mathrm{~K}$ and $318 \mathrm{~K}$ respectively for $\mathrm{T}_{1}$, and $\mathrm{T}_{2}$

The average value of Ea, 27.40 for the Spider Wisp / Cat's Whiskers is lower than $40.0 \mathrm{kJmol}^{-1}$ (Onen and Jacob, 2016; Onen and Nwufo, 2007), implying that the inhibitors are physically adsorbed on the mild steel surface.

The values of heat of adsorption, Qads as reflected in Table 2 were determined from the relation

Qads $=19.147\left(\log \frac{\theta 2}{1-\theta 2}-\log \frac{\theta 1}{1-\theta 1}\right)\left(\frac{T 1 T 2}{T 2-T 1}\right)$

where $\theta_{1}$ and $\theta_{2}$ are surface coverage at $308 \mathrm{~K}$ and $318 \mathrm{~K}$ respectively for $\mathrm{T}_{1}$ and $\mathrm{T}_{2}$.

All the values of Qads, having mean of $-13.95 \mathrm{kJmol}^{-1}$ for inhibitor Spider Wisp / Cat's Whiskers as recorded in Table 2 is an indication that the inhibition efficiency and adsorption decrease with increase in temperature which agrees with reports by Onen and Jacob (2016); Onen and Nwufo(2007).The negative value of Qads also suggest that interactions occurred between adsorbed inhibitor molecules and the MS is spontaneous; a property of strong inhibitor-metal surface interaction.

\subsection{Adsorption Analysis of the Results}

It is clear from Table 1 and Fig. 3 that the inhibition efficiency $\left(\% \mathrm{I}_{\mathrm{E}}\right)$ and surface coverage $(\theta)$ increased with inhibitor concentration and decreased with increasing temperature. This further confirms physisorption mechanism for the inhibition process, (Onen and Nwufo, 2008). The high surface coverage observed at high inhibitor concentrations is due to very strong interactions between the adsorbed species. The surface coverage values imply that the adsorption of the two extract (inhibitors) at the MS interface may be due to electrostatic force between the atoms on the metal surface and the adsorbate. This observation agrees with assertion made by Nooret al., (2016), Al Jahdaly and Awad (2016), Onen and Jacob, ( 2016); Onen and Nwufo (2007) and Onen and Nwufo, (2008).

Adsorption plays an important role in the inhibition of metallic corrosion by organic inhibitors. The efficiencies of inhibitors expressed as the relative reduction in corrosion rate can be quantitatively related to the amount of adsorbed inhibitors on the metal surface. It is assumed that the corrosion reaction are prevented from occurring over the active sites of the metal surface covered by adsorbed inhibitors species, whereas the corrosion reaction occurs normally on the surface at inhibitors free area (Chaurvediet al., 2012).

Attempts were made to fit experimental data to various isotherms including Frumkin, Langmuir, Temkin, Freundlich and Flory-Huggins isotherms. However the results were well fitted by Langmuir 
adsorption isotherms and have been used to describe the adsorption characteristic of the inhibitors. The Langmuir theory allows the most basic presentation of adsorption on an ideal surface. This isotherm is based on the assumption that all adsorption sites are equivalent and that particle binding occurs independently from nearby sites either being occupied or not, and may be written in the form:

$\frac{C}{\theta}=\frac{1}{\operatorname{Kads}}+C$

Where $C$ is the concentration of the inhibitor, $K_{a d s}$ is adsorption equilibrium constant and $\theta$, is the surface coverage (Dahmani et al., 2010).A straight line was obtained by plotting the graph of $\mathrm{C} / \theta$ vs C with the $\mathrm{R}^{2}$ (linear correlation coefficient) value almost unity $(0.98$, Fig. 5$)$. The slope is reported almost unity (i.e. one) suggesting that the Langmuir adsorptionisotherm model provides the best description of the adsorption behaviour(Dahmaniet al., 2010).

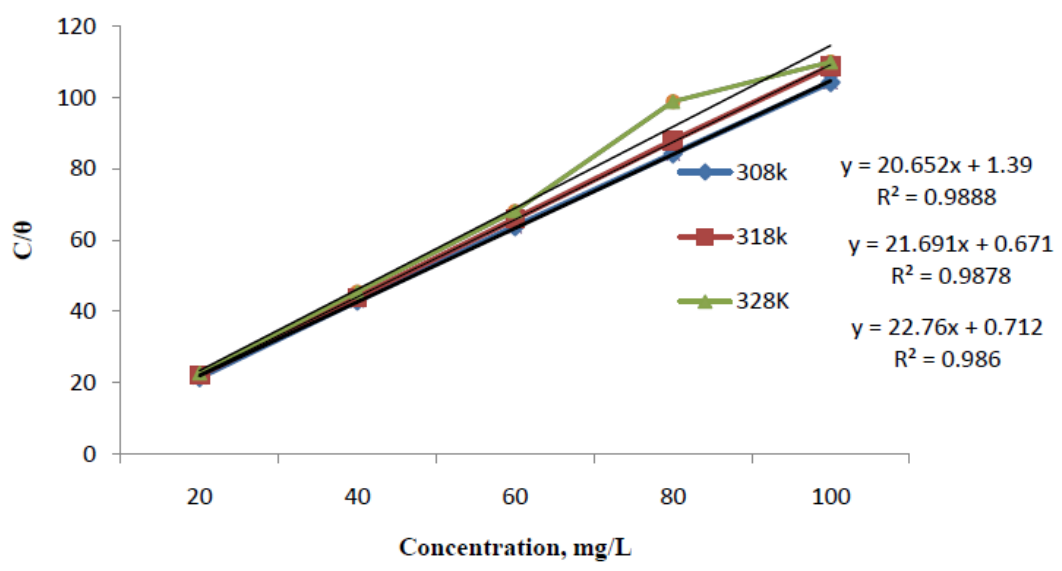

Fig5. Langmuir Adsorption Isotherm for MS in $0.1 \mathrm{M} \mathrm{HCl}$ containing various Concentrations of extract Spider Wisp / Cat's Whiskers at different temperatures

Corrosion rate of the MS decreases with increasing concentration of the extracts (Fig. 2), also, corrosion rate decreases with increasing in temperature. The inhibition efficiency also increases with increasing concentration of the extracts (Fig. 3), suggests that the extract molecules act by adsorption on the metal surface. Consequently, the increasing of the inhibition efficiency was ascribed to the increase in surface coverage. It was observed that corrosion inhibition efficiency decreased with increasing temperature and the best efficiency was obtained at $308 \mathrm{~K}$ as a result of increase in the adsorption of extract molecules.

The corrosion process kinetics acquire the character of a diffusion process, in which at higher temperature, the quantity of extract (inhibitor) molecules present at the metal surface is lower than at lower temperatures. The enhancement of inhibition efficiency at lower temperatures may be due to high activation energy available for adsorption, and the higher rate of diffusion of inhibitor molecules. This assertion is strongly supported by Al Jahdaly etal., (2016), Onen and Nwufo (2007); Onen and Nwufo (2008); Onen et al., (2010).

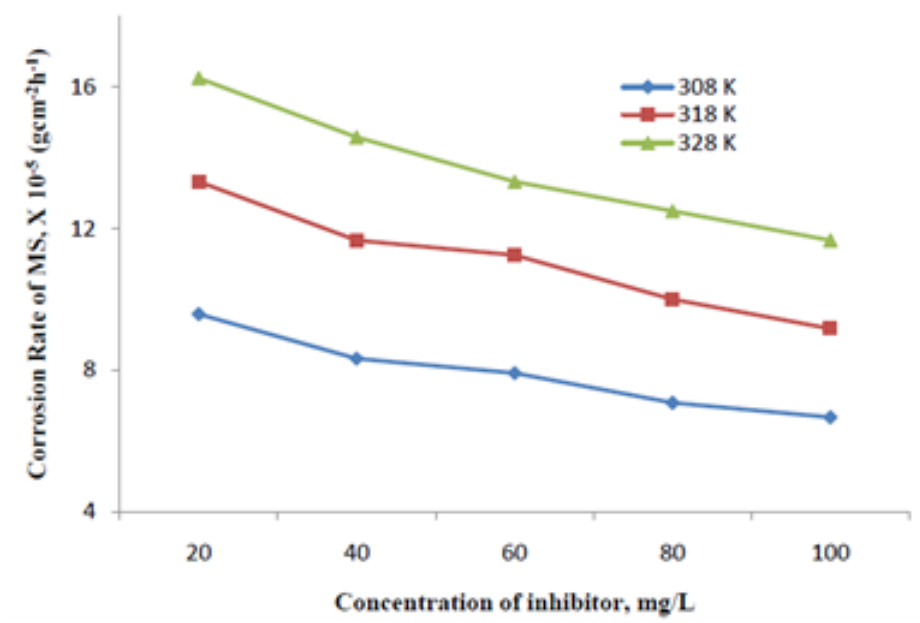

Fig6. Plot of Corrosion rate of MS against various Concentration of Inhibitor Spider Wisp / Cat's Whiskers at $308 \mathrm{~K}, 318 \mathrm{~K}$ and $328 \mathrm{~K}$ respectively 
Chemical and Electrochemical Investigations of Spider Wisp / Cat's Whiskers (Cloeme Gynandra) as Corrosion Inhibitor for Mild Steel in Hydrochloric Acid Medium

Table4.3. Data obtained from Potentiodynamic Polarization curves shown in Fig. 4.8 and 4.9 for MS Electrode in $0.1 \mathrm{M} \mathrm{HCl}$ in different Concentrations of the extracts at $308 \mathrm{~K}$

\begin{tabular}{|c|c|c|c|c|c|c|}
\hline Sample & $\begin{array}{l}\text { Conc. } \\
\text { (mg/L) }\end{array}$ & \begin{tabular}{|l|}
$-E_{\text {corr }}$ \\
(V) vSAg/AgCl Sat, 3M \\
KCl \\
\end{tabular} & $\begin{array}{l}I_{\text {corr }} \\
\left(\times 10^{-5} \mathrm{Acm}^{-2}\right)\end{array}$ & \begin{tabular}{|l}
$-\beta_{\mathrm{c}}$ \\
$\left(\mathrm{mVdec}{ }^{-1}\right)$
\end{tabular} & $\begin{array}{l}\mathrm{B}_{\mathrm{a}} \\
\left(\mathrm{mVdec}{ }^{-1}\right)\end{array}$ & $\begin{array}{l}\eta_{\mathrm{p}} \\
(\%)\end{array}$ \\
\hline \begin{tabular}{|l|} 
Blank \\
\end{tabular} & 0.000 & 0.426 & 683.100 & 0.626 & 0.523 & - \\
\hline $\begin{array}{l}\text { Spider Wisp } \\
\text { / Cat's } \\
\text { Whiskers }\end{array}$ & 20 & 0.242 & 43.65 & 0.441 & 0.366 & 93.61 \\
\hline " & 40 & \begin{tabular}{|l|}
0.330 \\
\end{tabular} & 37.09 & \begin{tabular}{|l|}
0.529 \\
\end{tabular} & 0.425 & 94.57 \\
\hline “ & 60 & 0.256 & 33.88 & 0.456 & 0.337 & 95.04 \\
\hline “ & 80 & 0.233 & 28.28 & \begin{tabular}{|l|l|}
0.433 \\
\end{tabular} & 0.337 & 95.86 \\
\hline " & 100 & \begin{tabular}{|l|}
0.304 \\
\end{tabular} & 25.68 & \begin{tabular}{|l|l|}
0.503 \\
\end{tabular} & 0.413 & 96.24 \\
\hline
\end{tabular}

\subsection{Polarization Measurements}

The electrochemical parameters proved that corrosion current $\left(\mathrm{I}_{\text {corr }}\right)$ density decreases in the presence of plant extract and the inhibition rate $\left(\% \eta_{\mathrm{p}}\right)$ increases with increasing extract concentration. These findings provide evidence for the inhibitive effect of the plant extract in $\mathrm{HCl}$ medium. The values of both anodic and cathodic Tafel constants $\beta_{\mathrm{a}}$ and $\beta_{\mathrm{c}}$ respectively have changed in the presence of the extract. The extract influences both the anodic and cathodic overpotentials and shifts Tafel lines in positive and negative directions respectively. This result confirms the mixed inhibition mode of the extract (Allaouiet al., 2013).

Fig.7 show polarization curves for the inhibition characteristics of Spider Wisp / Cat's Whiskers. These curves show anodic and cathodic polarization plots recorded on MS electrode in $0.1 \mathrm{M} \mathrm{HCl}$ at various concentrations $(20,40,60,80$ and $100 \mathrm{mg}$ of extracts, and also, 0.02, 0.04, 0.06, 0.08, and $0.1 \mathrm{M} \mathrm{HCl})$ in the presence and absence of the extracts. As would be expected both anodic and cathodic reactions of MS electrode corrosion were enhence with the increase in extracts concentration. This result suggests that the addition of the extracts reduces anodic and cathodic dissolution and also retards the hydrogen evolution reaction. Table 3 shows the calculated inhibition efficiency, $\eta_{\mathrm{p}}(\%)$ as reported from the following equation;

$\eta p(\%)=\frac{(I-I \text { cor })}{\left(I^{\circ} \text { corr }\right)} \times 100$

where $\mathrm{I}_{\text {corr }}^{\mathrm{o}}$ and $\mathrm{I}_{\text {corr }}$ correspond to uninhibited and inhibited current densities, respectively. The inhibition efficiencies of the extract were ranging between $94 \%$ and $96 \%$.

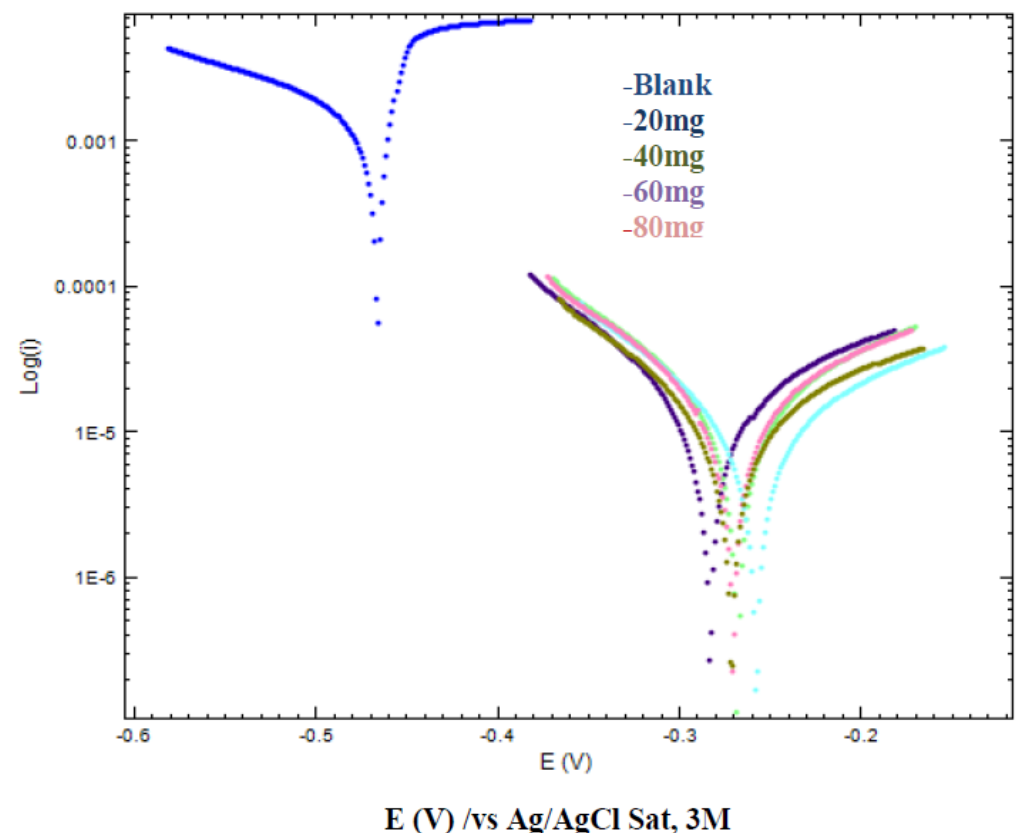

Fig7. Potentiodynamic Polarization curves of $\mathrm{MS}$ Electrode in $0.1 \mathrm{M} \mathrm{HCl}$ without and with various Concentrations from Spiderwisp 
Table4. Summary of Results of Phytochemical Screening of the Methanolic leaves extracts of Spider Wisp / Cat's Whiskers

\begin{tabular}{|l|l|l|l|l|l|l|}
\hline Sample & Tannins & Saponins & Alkaloids & Flavonoids & Cardiac glycosides & Anthraquinones \\
\hline $\begin{array}{l}\text { Spider Wisp / } \\
\text { Cat's } \\
\text { Whiskers }\end{array}$ & + & - & + & + & + & - \\
\hline
\end{tabular}

$+=$ Presence of Phytochemical

- = Absence of Phytochemical

\subsection{Characterization of Plants Extract by FT-IR Spectroscopy}

Fig.8 shows the transmission vibrational spectrum of Spider Wisp / Cat's Whiskers. Original absorption are at 3400or $3394 \mathrm{~cm}^{-1}$ for the samples respectively (associated hydroxyl) was overlapped by the strong stretching mode of $\mathrm{O}-\mathrm{H}$, and that at 2921 or $2854 \mathrm{~cm}^{-1}$ is related to $\mathrm{C}-\mathrm{H}$ strong stretching and $\mathrm{O}-\mathrm{H}$ very broad, strong stretching vibration. The $\mathrm{C}-\mathrm{F}, \mathrm{C}-\mathrm{N}$, and $\mathrm{C}-\mathrm{O}$ absorption bands at 1270 $\mathrm{cm}^{-1}$ observed for Spider Wisp / Cat's Whiskers could be assigned to the strong stretching of alkyl halide; medium stretching in amine; and strong stretching in acid. Besides these, there are absorption bands at 1033 or $1029 \mathrm{~cm}^{-1}$, which can be ascribed to the C-F or C-O stretching vibration. At $753 \mathrm{~cm}^{-}$ ${ }^{1} \mathrm{C}-\mathrm{H}$ of strong bending alkenes and $\mathrm{C}-\mathrm{Cl}$ of strong stretching alkyl halide observed for Spider Wisp / Cat's Whiskers, and $534 \mathrm{~cm}^{-1}$ for strong stretching C-Br. (Satapathyet al., 2009).

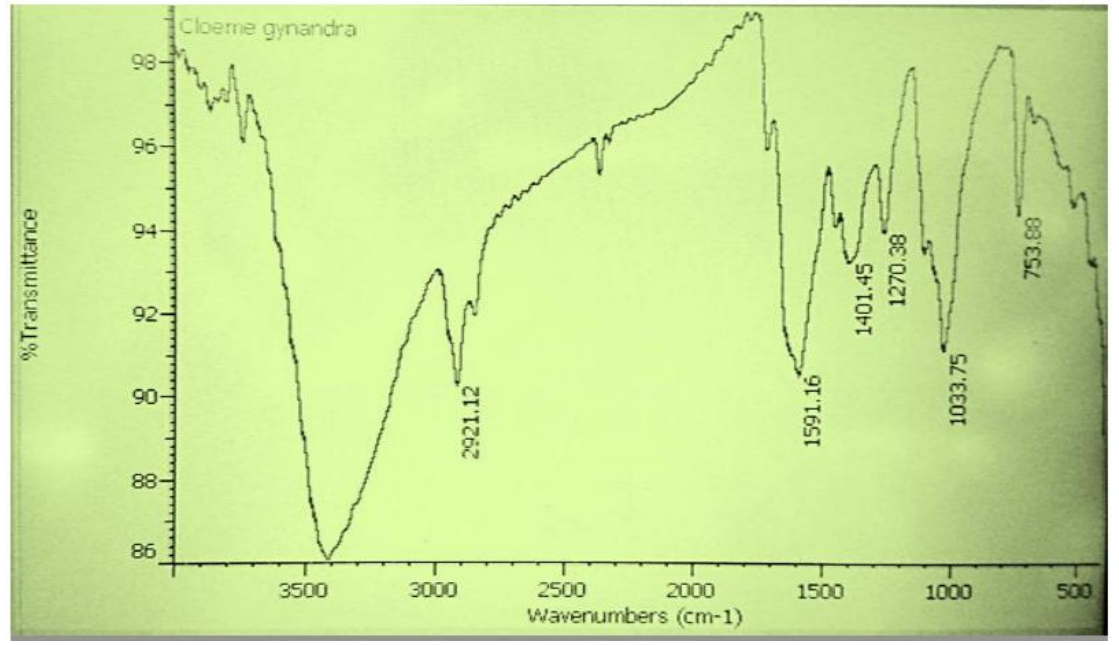

Fig8. FT-IR Spectrum of Spider Wisp / Cat's Whiskers (Cloeme gynandra)

\section{Conclusions}

The inhibitor Spider Wisp / Cat's Whiskers (Cloeme gynandra) studied retarded the acid corrosion of MS to a large extent; being physically adsorbed on the metal surface. Inhibition efficiencies $\left(\% \mathrm{I}_{\mathrm{E}}\right)$ increased with increasing concentration but decrease with temperature increase. A linear variation was observed from the plots which signify first order kinetics for the inhibition process.

Inhibition by the extracts obeys the mechanism of physisorption, as seen from the experimental observations. The values of Qads obtained at $308 \mathrm{~K}$ and $318 \mathrm{~K}$ are all negative indicating that the inhibitor is strongly adsorbed on steel surface and the adsorption is spontaneous.

Langmuir adsorption isotherm was also found to be suitable for the experimental results and has been used to describe the adsorption characteristics of the inhibitors.

The electrochemical parameters show that corrosion current $\left(\mathrm{I}_{\text {corr }}\right)$ density decreases in the presence of plant extract and the inhibition rate increases with increasing extract concentration. These findings provide evidence for the inhibitive effect of the plants extract in $\mathrm{HCl}$ medium. This result confirms the mixed inhibition mode of the extract.

The presence of Tannin, Alkaloid and Flavonoid and is also an evidence of the inhibition potency of the extract. FT-IR results indicate that Spider Wisp / Cat's Whiskers (Cleome gynandra) contain heteroatom such as $\mathrm{O}, \mathrm{N}$, and multiple bonds in the molecule through which they adsorption takes place on the metal surface. 


\section{REFERENCES}

Ahamad, I. Prasad, R. Quraishi, M.A., (2010). Corrosion Science, 52 (2010) 3033-3041.

Allaoui, M. A. Cheriti , N. Gherraf, E. Chebouat I., B. Dadamoussa I., and R. Salhi.,(2013).Inhibition of Mild Steel Corrosion in $1 \mathrm{M} \mathrm{HCl}$ Medium by Acid Extract of Haloxylonscoparium Pomel. International Journal Electrochemical Science, 9432

Al Jahdaly, B.A and Awad, M.I (2016); Enhanced Inhibition of Corrosion of Mild Steel by Triazole Derivative in presence of Copper ions, International Journal of Electrochemical Science, 11, $5473-5480$.

Al - Senani, M (2016); Corrosion Inhibition of Carbon Steel in Acidic Chloride Medium by Cucumissativus (Cucumber) Peel Extract, International Journal of Electrochemical Science, 11, $291-302$.

Aydogdu, G.H, and Aydinol, M.K.,(2006). Determination of susceptibility to intergranular corrosion and electrochemical reactivation behaviourof AISI 316L type stainless steel. Corrosion Science, 3565-3583

Chaurvedi,A; TripathiR and Upadhayay,R. K. (2012). Corrosion Inhibitory Effects of Some Substituted Thiourea on Mild Steel in Acid Media. Research Journal of Chemical Science, 18-27

Dahmani,M.,Touhami,E.T., Al-Deyab, S.S., Hammouti, B and Bouyanzer, A.(2010). Corrosion Inhibition of C38 Steel in 1M HCl: A Comparative Study of Black Pepper Extract and its Isolated Piperine, International Journal of Electrochemical Science, 5, 1060-1069

Griffths, P. and De-Hasseth, J.I. (2007).Fourier Transform Infrared Spectrometry. $2^{\text {nd }}$ edition, Willey Blackwell. 7-18

Guannan M., Libin T. and Xueming L., (2002).Corrosion Inhibition Synergism between Lanthanum (III) Ion and 8-Hydroxyquinoline for Zinc in Hydrochloric Acid, Journal of Rare Earths, 502506

Hammouti,B., Patel,N. S., Jauhariand,S., Mehta,G.N., Al-Deyab, S. S. and Warad, I.(2013).Mild Steel Corrosion Inhibition by various Plants Extracts in $0.5 \mathrm{M}$ Sulphuricacid. International Journal of Electrochemical Science, 2635-2655

Manimegalai, M., Rajeswari, P., Manithamuthu, S., and Palanisawamy, N.,(2000). Biocidal and Inhibition Effect of Natural Occuring Substances- Azadirachta indica on Mild Steel in fresh water, Proc. of $10^{\text {th }}$ National Congress on Corrosion Control, Held Sept. 6-8,2000. Madurai, India. 153

Noor, E.A, Al-Moubaraki, A, Al-Zhrani, A. H and Hubani, M. H (2016); Testing and Comparing the Inhibitory Action of Red Onion Seeds and Peels Extracts on the Corrosion of Steel in Phosphoric Acid, International Journal of Electrochemical Science, 11 , 6523-6539

Oguzie, E. E., Enenebeaku, C. K., Akalezi, C. O., Okoro, S. C., Ayuk, A. A., and Ejike, E.N.,(2014). "Adsorption and corrosion-inhibiting effect of Dacryodisedulis extract on low-carbon-steel corrosion in acidic media," Journal of Colloid and Interfacial Science, 283-292

Onen, A. I., and Nwufo, B.T. (2007). "Inhibitory action of Bromothymol blue and Dimethyl yellow on aluminium corrosion in $\mathrm{H}_{2} \mathrm{SO}_{4}$ ", Indian Bulleting of Pure \&Applied Science, 1-15

Onen, A. I. and Nwufo, B.T. (2008). "Cassia Siamea Lam Leaves Extract as a Corrosion Inhibitor of Mild Steel in $\mathrm{H}_{2} \mathrm{SO}_{4}$ Solutions", International Journal of Chemical Science, 77-87

Onen,A. I.,Nwufo, B. T., Ebenso, Eno E. and Reuben M. H. (2010). Titanium (IV) Oxide as Corrosion Inhibitor for Aluminium and Mild Steel in Acidic Medium. International Journal of Electrochemical Science, 1563 - 1573

Onen,A. I., Barminas, J.T. and Jacob, J.,(2013).Inhibitory Action of Ficuscarica Extractson AluminiumCorrosion in Acidic Medium.Chemical Science Transactions, 1326-1333

Onen, A. I and Jacob, J. (2016); Ficuscarica and Vitellariaparadoxa Leaf Extracts as Inhibitors of Brass Corrosion in Acidic Medium, International Journal of Advanced Research in Chemical Sciences : 3 (8), $34-40$.

Satapathy, A. K., Gunasekaran, G., Sahoo, S. C., Amit, K. and Rodrigues, P. V., (2009). Corrosion Inhibition by Justiciagendarussa Plant Extract in Hydrochloric Acid Solution, Corrosion Science, 51 (12) 2848 - 2856. 